OPEN ACCESS

Edited by: Banasri Hazra

Jadavpur University, India

Reviewed by:

Yun K. Tam

Sinoveda Canada Inc., Canada Ulrike Lindequist,

University of Greifswald, Germany

*Correspondence:

Chau Ling Tham

chauling@upm.edu.my

Specialty section:

This article was submitted to

Ethnopharmacology,

a section of the journal

Frontiers in Pharmacology

Received: 30 January 2018

Accepted: 31 May 2018

Published: 20 June 2018

Citation:

Tan JW, Israf DA and Tham CL (2018)

Major Bioactive Compounds

in Essential Oils Extracted From the Rhizomes of Zingiber zerumbet (L)

Smith: A Mini-Review on the Anti-allergic and Immunomodulatory Properties.

Front. Pharmacol. 9:652. doi: 10.3389/fphar.2018.00652

\section{Major Bioactive Compounds in Essential Oils Extracted From the Rhizomes of Zingiber zerumbet (L) Smith: A Mini-Review on the Anti-allergic and Immunomodulatory Properties}

\author{
Ji Wei Tan 1,2, Daud Ahmad Israf' and Chau Ling Tham ${ }^{1 *}$ \\ ${ }^{1}$ Department of Biomedical Science, Faculty of Medicine and Health Sciences, Universiti Putra Malaysia, Seri Kembangan, \\ Malaysia, ${ }^{2}$ School of Science, Monash University Malaysia, Bandar Sunway, Malaysia
}

Zingiber zerumbet ( $L$ ) Smith is part of the Zingiberaceae family, one of the largest families of the plant kingdom. Z. zerumbet is a perennial, aromatic and tuberose plant that grows in humid locations where its center of distribution is located in the South-East Asia region. This plant has been traditionally used in foods and beverages and for ornamental purposes. Although many studies have reported on the biomedical applications of $Z$. zerumbet, the anti-allergic effects of $Z$. zerumbet and its major bioactive compounds have not yet been summarized in detail. Many major metabolites that have been reported to contain anti-allergic properties are terpene compounds which can be found in the essential oil extracted from the rhizomes of $Z$. zerumbet, such as zerumbone, limonene, and humulene. The rhizome is among the part of $Z$. zerumbet that has been widely used for many studies due to its exceptional biomedical applications. Most of these studies have shown that the essential oil, which can be obtained through hydro-distillation of the rhizomes from $Z$. zerumbet, is enriched with various active metabolites. Therefore, this mini-review provides an overview of the main aspects related to the anti-allergic and immunomodulatory properties of the major bioactive compounds found in the essential oils extracted from the rhizomes of $Z$. zerumbet, with the aim of demonstrating the importance of essential oil extracted from the rhizomes of $Z$. zerumbet and its bioactive compounds in the treatment of allergy and allergyrelated diseases, in addition to other widely reported and extensively studied biomedical applications.

Keywords: Zingiber zerumbet, rhizome, essential oil, anti-allergic, immunomodulatory, mini-review

\section{INTRODUCTION}

Zingiberaceae is the largest families of the plant kingdom. Its plants tend to be high in medicinal values and provide many useful products for food, spices, medicines, dyes, perfume and esthetics (Jantan et al., 2003; Koga et al., 2016). Zingiber is a genus of Zingiberaceae with approximately 141 species (Sirirugsa, 1995). Zingiber zerumbet (L) Smith is a wild ginger belonging to the Zingiber 
genus and is well-known among local cultures as "Lempoyang," "Ghatian," "Yaiimu," "Jangli adha," "Awapuhi," "Zurunbah," "Hong Qiu Jiang," and "Hiao Dam." This particular type of wild ginger grows naturally in damp, shaded parts of the low land and is believed to be native to India and the Malaysian Peninsula (Yob et al., 2011). The traditional uses of ginger are broad, including but not limited to the treatment of nausea, hangovers, migraine headache, morning and motion sickness, worm infestation in children, as well as cuts and bruised skin (Nik Norulaini et al., 2009; Butt and Sultan, 2011; Sahebkar, 2011). Various local groups have been using ginger to provide remedy against allergic diseases including asthma and sinusitis for centuries (Butt and Sultan, 2011; Sahebkar, 2011). As one type of wild ginger, the crude extract as well as the active compounds extracted from the rhizome and leaves of $Z$. zerumbet have been reported to possess various pharmacological properties including anti-inflammatory (Murakami et al., 2002; Jalil et al., 2015), antitumoral (Rashid and Pihie, 2005; Takada et al., 2005; Abdelwahab et al., 2010), antioxidant (Ruslay et al., 2007; Rout et al., 2011), antibacterial (Kumar et al., 2013), antiviral (Epstein-Barr virus) (Murakami et al., 1999), analgesic (Somchit et al., 2005), antiallergic (Tewtrakul and Subhadhirasakul, 2007) characteristics and usefulness for treating stomach problems (Prakash et al., 2011).

\section{THE ANTI-ALLERGIC AND IMMUNE MODULATION ACTIVITIES OF Z. zerumbet}

Although there have been quite a number of studies conducted to study the effectiveness of $Z$. zerumbet in a broad range of biological activities related to human health, there has been very few reported studies of $Z$. zerumbet as well as its bioactive compounds focusing on anti-allergy. Increasing levels of allergic diseases, such as allergic rhinitis (AR), atopic dermatitis, asthma and food allergies in many of the developed countries (Carlsen, 2003) are causing significant health problems, especially in children. Therefore, various research has been carried out extensively to combat these diseases (Pawankar et al., 2013). In one of the studies, the ethanolic and aqueous extraction of $Z$. zerumbet were subjected to an in vitro investigation for its anti-allergic activities (Tewtrakul and Subhadhirasakul, 2007). This study has shown that the ethanolic and aqueous extracts of $Z$. zerumbet $(10-100 \mu \mathrm{g} / \mathrm{mL})$ inhibited the release of $\beta$-hexosaminidase from RBL-2H3 cells as much as $8.4-53.7 \%$ $\left(\mathrm{IC}_{50}=91 \mu \mathrm{g} / \mathrm{mL}\right)$ and $10.9-59.1 \%\left(\mathrm{IC}_{50}=68.2 \mu \mathrm{g} / \mathrm{mL}\right)$, respectively. Several patents were filed due to the exceptional anti-allergic activities shown by $Z$. zerumbet. Among which, a patent by Chaung et al. (2009) provides a method of preparing polar solvent extraction from the root of $Z$. zerumbet as well as the use of this formulation to prevent or to treat an allergic disorder. Another patent by Lin et al. (2013) provides a method of preparing solvent extraction by using ethanol, water, or a mixture of both from the root of $Z$. zerumbet for treating AR or allergic eczema.
The essential oils from rhizomes of $Z$. zerumbet have also been shown to contain several beneficial effects such as analgesic activity (Sulaiman et al., 2010), anti-nociceptive activity (Khalid et al., 2011), and anti-microbial activity (Kader et al., 2010). However, anti-allergic activities involving the essential oils extracted from the rhizomes of $Z$. zerumbet are still yet to be well-reported. Hence, this mini-review focuses on the major bioactive compounds found in the essential oils extracted from the rhizomes of $Z$. zerumbet which have been reported to possess anti-allergic and immunomodulatory properties in order to improve the understanding on the use of $Z$. zerumbet and its bioactive compounds in the treatment of allergy and allergicrelated diseases.

\section{THE ANTI-ALLERGIC AND IMMUNOMODULATORY ACTIVITIES OF THE MAJOR BIOACTIVE COMPOUNDS IN THE ESSENTIAL OILS EXTRACTED FROM THE RHIZOMES OF Z. zerumbet}

Currently, there are only a few zingiber genus that have been reported to contain anti-allergic properties, including $Z$. officinale, Z. cassumunar, Z. zerumbet, and Z. mioga (Tewtrakul and Subhadhirasakul, 2007; Shin et al., 2015). The major bioactive compounds which can be found in the essential oil of $Z$. officinale are $\alpha$-zingiberene (17.4-32.2\%), $\beta$-sesquiphellandrene (6.6-27.16\%), and geranial (25.9\%); for Z. cassumunar is sabinene (36.71-53.50\%); for Z. zerumbet are zerumbone (35.5-84.8\%) and pinene (10.3\% to $31.4 \%)$; for Z. mioga is $\beta$-phellandrene (26.60\%) (Kurobayashi et al., 1991; Sharifi-Rad et al., 2017). Interestingly, zerumbone was found to be exclusively and abundantly present $(>80 \%)$ in the essential oil extracted from the rhizomes of $Z$. zerumbet, in comparison to other major bioactive compounds extracted from $Z$. officinale, $Z$. cassumunar and Z. mioga. According to Shieh et al. (2015), the anti-allergic effects of $Z$. zerumbet may be due to zerumbone as this compound has been shown to effectively inhibit asthma in mice. Apart from zerumbone (35.5-84.8\%), the other major compounds that can be found in the essential oils extracted from the rhizomes of $Z$. zerumbet are pinene (10.3-31.4\%), humulene (10.03-17.23\%), linalool (7.7-17.1\%), caryophyllene (6.9-10.2\%), borneol (4.78\%), and limonene (0.8-1.3\%) (Figure 1). Among which, it is interesting to note that limonene can only be found in Z. zerumbet but not the other Zingerber genus (Sun, 2007; Bhuiyan et al., 2008).

The biomedical applications of some of these major bioactive compounds found in $Z$. zerumbet have been previously summarized in several review papers (Calderón-Montaño et al., 2011; Singh et al., 2012; Kalantari et al., 2017). However, the antiallergic properties of these major bioactive compounds were not included. In this review, the major bioactive compounds found in the essential oils extracted from the rhizomes of $Z$. zerumbet, such as zerumbone, limonene, borneol, pinene, linalool, humulene, and caryophyllene, and their reported anti-allergic and immune modulation activities are summarized in Table $\mathbf{1}$. 


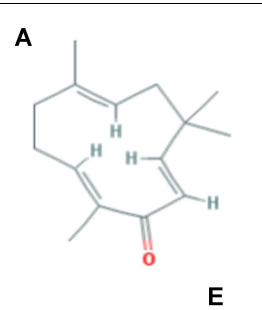

E

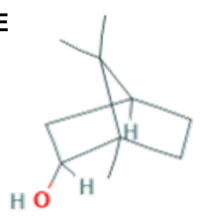

B

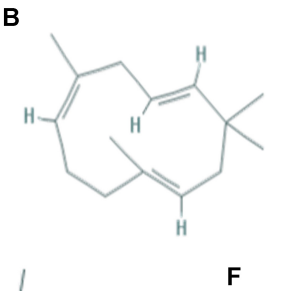

$\mathbf{F}$

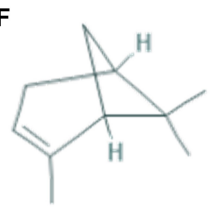

C

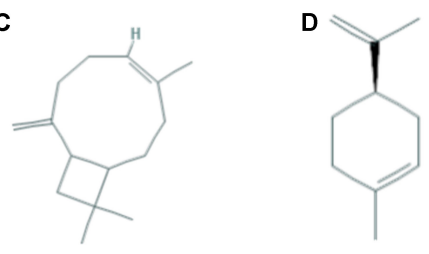

G

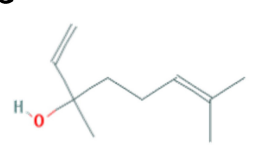

FIGURE 1 | The chemical structure of some of the major bioactive compounds that can be found in Zingiber zerumbet. (A) Zerumbone (B) $\alpha$-Humulene (C) trans-Caryophyllene (D) Limonene (E) Borneol (F) $\alpha$-Pinene (G) Linalool.

\section{Zerumbone}

Zerumbone is a sesquiterpene compound abundantly present (35.5-84.8\%) in essential oils extracted from the rhizomes of Z. zerumbet (Tewtrakul and Subhadhirasakul, 2007; Sharifi-Rad et al., 2017). A study done by Shieh et al. (2015) showed that zerumbone isolated from $Z$. zerumbet decreased the severity of airway hyperresponsiveness and the accumulation of eosinophils in bronchoalveolar lavage fluid (BALF) collected from OVA-challenge female BALB/c mice. The oral administration of zerumbone $(0.1,1$, and $10 \mathrm{mg} / \mathrm{kg})$ also significantly reduced serum anti-OVA IgE levels in mice (Shieh et al., 2015), which further resulted in the reduction of OVA-induced cytokine secretions (IL-4, IL-5, IL-10, and IL-13) in the BALF collected (Shieh et al., 2015). Thus, the authors speculated that zerumbone may have an anti-allergic effect on allergic asthma by suppressing Th2-related cytokines (IL-4, IL-5, IL-10, and IL-13) secretion and consequently reducing IgE production by $\mathrm{B}$ cells (Shieh et al., 2015). The data reported in this study was the first known report to provide a rationale for extensive preclinical studies on zerumbone in IgE-mediated allergic asthma.

\section{Pinene}

Pinene is a monoterpene compound that can be isolated from Z. zerumbet (Koga et al., 2016) in relatively higher quantities (10.3-31.4\%) than other plants from the same genus. The percentages of pinene found in $Z$. corallinum and $Z$. cassumunar were only $2.16-3.23 \%$ and $5.2-7.25 \%$, respectively (Koga et al., 2016). In addition, pinene has been reported to attenuate OVA-induced $\mathrm{AR}$ in female $\mathrm{BALB} / \mathrm{c}$ mice by decreasing the infiltration of eosinophils and mast cells in AR nasal mucosa tissue, as well as reducing the level of TNF- $\alpha$ and number of nose rubs in mice orally pre-treated with $\alpha$-pinene $(0.1,1$, or $10 \mathrm{mg} / \mathrm{kg})$ (Nam et al., 2014). The authors even demonstrated that posttreatment of $\alpha$-pinene in the OVA-induced mice significantly decreased nasal mucosa IgE level and the number of nose rubs (Nam et al., 2014). The in vitro study also reported that $\alpha$-pinene $(0.1,1$, or $10 \mu \mathrm{g} / \mathrm{mL})$ inhibits the production and mRNA expression of TNF- $\alpha$ in PMACI-induced activation of HMC-1 cells (Nam et al., 2014). In term of regulatory mechanism of $\alpha$-pinene on allergic inflammation, this compound inhibits PMACI-induced activation of NF-KB and IKK- $\beta$ in HMC- 1 cells (Nam et al., 2014). In conclusion, that study suggested that $\alpha$-pinene was able to exert its anti-allergic effects by interfering the NF- $\kappa \mathrm{B} / \mathrm{I} \kappa \mathrm{B}$ signaling pathway as this pathway is closely related with the inhibition of allergic inflammation in human mast cells (Singh et al., 2011).

\section{Humulene}

Similar to zerumbone, humulene is a sesquiterpene compound that can be found abundantly (10.03-17.23\%) in Z. zerumbet (Baby et al., 2009). Its key enzyme, $\alpha$-humulene synthase, has been shown to play a part in the synthesis of zerumbone (Baby et al., 2009). However, other Zingiber species such as $Z$. nimmonii and $Z$. cassumunar have been shown to contain higher levels of humulene (19.6-27.7\% and 23.92\%, respectively), in comparison to Z. zerumbet. Rogerio et al. (2009) reported on the inhibitory effect of $\alpha$-humulene on OVA-induced airway allergic inflammation in female BALB/c mice. They showed that therapeutic treatment with $\alpha$-humulene $(50 \mathrm{mg} / \mathrm{kg})$ may be able to decrease leukocyte recruitment (neutrophils, eosinophils and mononuclear) as well as allergic associated mediators including leukotriene (LT) $\mathrm{B}_{4}$ and IL-5 levels in the BALF (Rogerio et al., 2009). The immunohistochemistry staining in this study also revealed the inhibitory effects of $\alpha$-humulene on the phosphorylation of p65 NF-kB and c-Jun AP-1 subunits, which are the two important modulators for the control production of the Th2 cytokine, IL-5 and the recruitment of leukocytes (Rogerio et al., 2009). These results suggest the potential of $\alpha$-humulene as a candidate for the treatment of asthma and other allergic diseases.

\section{Linalool}

Linalool is a monoterpene in $Z$. zerumbet that contributes to the aromatic scent of this plant (7.7-17.1\%) (Baby et al., 2009). In one study, linalool and other 20 types of natural compounds were shown to inhibit $\beta$-hexosaminidase release at the concentration of $100 \mu \mathrm{g} / \mathrm{mL}$ in RBL-2H3 cells induced with calcium ionophore, A23187 (Mitoshi et al., 2014). The study also demonstrated the protective effects of orally administered linalool $(100 \mathrm{mg} / \mathrm{kg})$ 


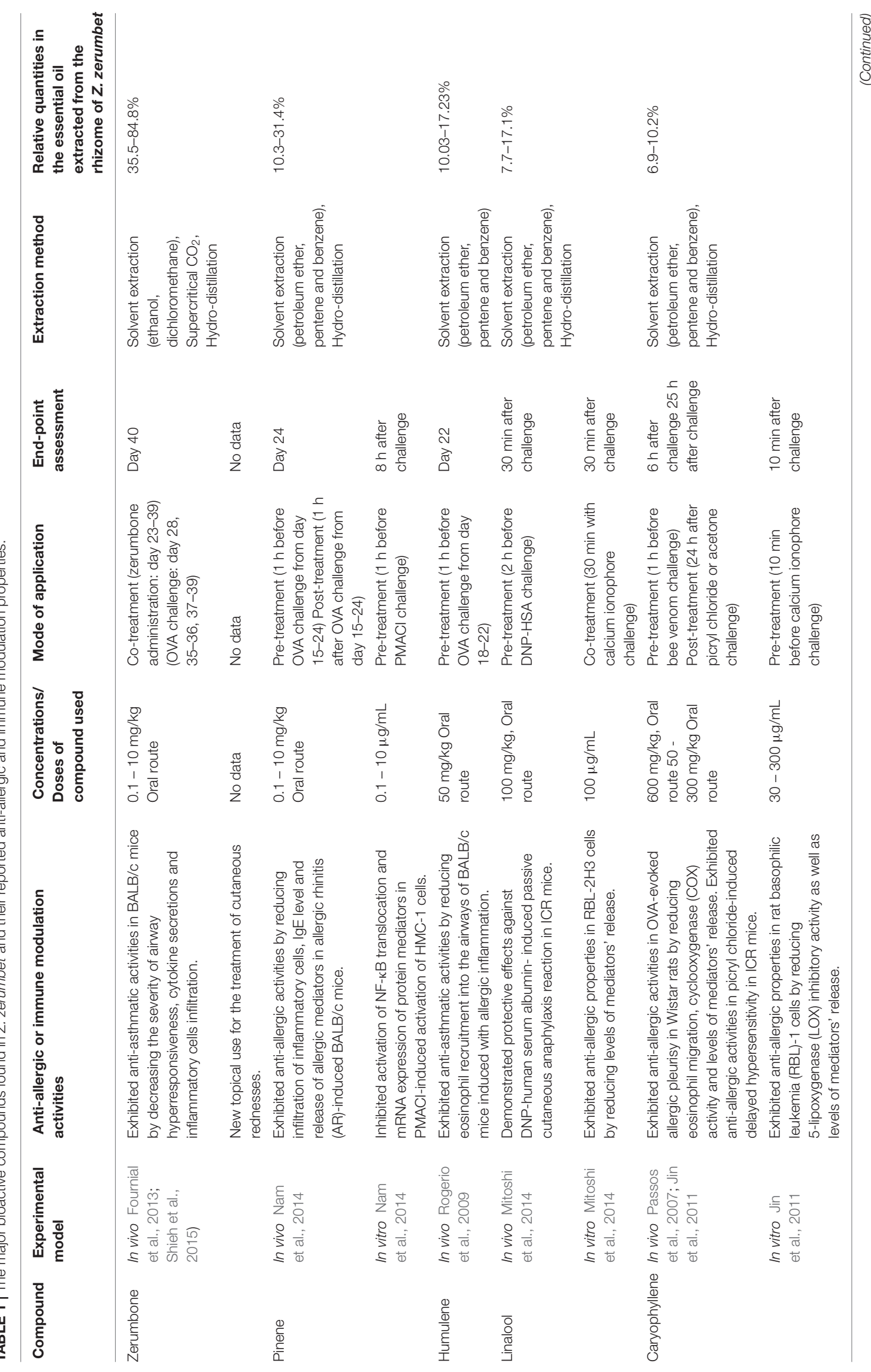


against DNP-HSA induced passive cutaneous anaphylaxis (PCA) reaction in mice whereby linalool significantly reduced the amount of Evans blue dye present in the exudates collected from ear samples (Mitoshi et al., 2014). In the discussion it was hypothesized that the anti-allergic effects of linalool may be at least in part dependent on the inhibition of NF- $\kappa B$ activation (Mitoshi et al., 2014). However, further investigation should be carried out, as its underlying molecular mechanism remains unelucidated.

\section{Caryophyllene}

Caryophyllene, one of the natural bicyclic sesquiterpenes in $Z$. zerumbet, contributes to the spiciness taste of this plant (Baby et al., 2009). In comparison to $Z$. nimmonii and $Z$. officinale which have been reported to possess $26.9-42.2 \%$ and $15.29 \%$ of caryophyllene, respectively, $Z$. zerumbet has a relative lower quantity of caryophyllene (6.9-10.2\%). Studies have shown that the oral administration of caryophyllene significantly inhibited the oedematogenic response caused by Apis mellifera venom in the OVA-sensitized male Wistar rat paws (Passos et al., 2007). Furthermore, the administration of caryophyllene significantly reduced the eosinophil migration at the site of venom induction, leading to reduced levels of tumor necrosis factor alpha (TNF- $\alpha$ ), prostaglandin $\mathrm{E} 2\left(\mathrm{PGE}_{2}\right)$ and COX activity (Passos et al., 2007). These results strongly suggest the potential of caryophyllene in the treatment of allergic conditions.

Another study conducted by Jin et al. (2011) demonstrated that preincubation of caryophyllene $(100 \mu \mathrm{M})$ with rat basophilic leukemia-1 (RBL-1) was able to significantly reduce 5-LOX inhibitory activity as well as the release of cysteinyl LTs $\left(\mathrm{LTC}_{4} / \mathrm{D}_{4} / \mathrm{E}_{4}\right)$, and the effect was more prominent in comparison to the other two bioactive compounds of $Z$. zerumbet limonene and pinene (Jin et al., 2011). Caryophyllene also significantly attenuated the antigen-induced degranulation of $\beta$-hexosaminidase and phosphorylation of Lyn molecules in RBL-2H3 cell culture (Jin et al., 2011). Furthermore, the in vivo immune modulatory effects of caryophyllene were also demonstrated. Caryophyllene was able to significantly inhibit the picryl chloride-induced delayed type hypersensitivity (DTH) response in mice, when given orally $(100-300 \mathrm{mg} / \mathrm{kg})$, as evidenced by decreased measurements in the ear thickness of mice (Jin et al., 2011). These findings concluded that caryophyllene exerts anti-allergic activity against mast cell degranulation and offers immune modulatory effects against DTH.

\section{Limonene}

Limonene is the only major bioactive compound found exclusively in $Z$. zerumbet in the Zingiberaceae family (Koga et al., 2016). Limonene has shown a potent reduction in the airway inflammatory reactions with improving asthma symptoms in Dermatophagoides farinae-induced allergic airway inflammation of male BALB/c mice (Hirota et al., 2012). One study demonstrated a lowered level of serum total IgE, allergen specific IgG $\mathrm{I}_{1}$ and allergic associated mediators (IL-5 and IL-13) in mice after inhalation of limonene $(1 \mathrm{mg} / \mathrm{kg}$ ) (Hirota et al., 2012). Additionally, limonene was able to decrease AHR in mice 
by suppressing the number of eosinophils found in the collected BALF (Hirota et al., 2012). It also significantly reversed allergeninduced lung histopathological changes in mice by lowering perivascular and peribronchial infiltration of eosinophils, goblet cells hyperplasia, airway fibrosis and smooth muscle thickness (Hirota et al., 2012). These findings have shown that limonene may be beneficial as a prophylactic and therapeutic agent for asthma in the future.

\section{DISCUSSION}

Most major bioactive compounds found in the essential oils extracted from the rhizome of $Z$. zerumbet are terpene compounds with long hydrocarbon tails, generally resulting in low polarity (Jiang et al., 2016). As such, a few preferred ways of extracting terpene compounds from $Z$. zerumbet are hydrodistillation and solvent extraction using organic solvents such as ethanol and methanol; or non-polar solvents such as petroleum ether, pentene, hexane, and benzene (Kalantari et al., 2017). A previous study by Tewtrakul and Subhadhirasakul (2007) showed that an ethanolic extract of $Z$. zerumbet containing both polar and non-polar compounds exhibited exceptional antiallergic effects by inhibiting the release of $\beta$-hexosaminidase from RBL-2H3 cells. However, not much attention has been given to the anti-allergic effects of other extracts from $Z$. zerumbet and particularly essential oil, in which the main constituent is zerumbone. Although it has once been reported that the essential oil of $Z$. zerumbet failed to inhibit $\beta$-hexosaminidase, the reported yield of essential oil from the whole plant of $Z$. zerumbet in that study was only $3.0 \%$, in comparison to other studies reporting yields ranging from 5 to 13\% (Rashid and Pihie, 2005; da Silva et al., 2017). It is also important to note that the essential oils used in that particular study were extracted from the whole plant but not the rhizomes of $Z$. zerumbet alone (Tewtrakul and Subhadhirasakul, 2007). Low levels of bioactive compounds present in the yield in particular terpene compounds may be too low to significantly exhibit an anti-allergic response. Further studies should be carried out with higher yield of extracted essential oil from the rhizomes of $Z$. zerumbet. Distilled hexane can be added during the hydro-distillation process to increase the yield of oil extracted from $Z$. zerumbet (Nik Norulaini et al., 2009). It would be interesting to study whether the essential oils extracted from the rhizomes of $Z$. zerumbet exhibit anti-allergic response as the extracted oil particularly from the rhizomes of $Z$. zerumbet has been proven to have many beneficial properties such as analgesic activity (Sulaiman et al., 2010), anti-nociceptive activity (Khalid et al., 2011) and anti-microbial activity (Kader et al., 2010).

Due to the presence of various bioactive compounds in a plant extract, it is difficult to confirm which bioactive compound contributes to the intended beneficial effects in a disease model (Sasidharan et al., 2011; Katiyar et al., 2012). Therefore, it would be much preferable to identify and isolate the major bioactive compounds present in a plant extract and study them individually. Since many major bioactive compounds found in the essential oil extracted from the rhizomes of $Z$. zerumbet have been shown to be effective in treating allergic responses, it would be important to know whether the doses used in these studies are practical to be translated into clinical studies. The highest oral doses of $Z$. zerumbet extract used in rats and mice were 600 and $300 \mathrm{mg} / \mathrm{kg}$, respectively, equivalent to 97 and $24 \mathrm{mg} / \mathrm{kg}$ in humans, according to the human equivalent dose equation (Reagan-Shaw et al., 2016). In terms of bioactive compounds, the highest oral dose of purified zerumbone compound isolated from $Z$. zerumbet used in mice was $10 \mathrm{mg} / \mathrm{kg}$, which is equivalent to $0.81 \mathrm{mg} / \mathrm{kg}$ when translated for human consumption. When the translated doses of these bioactive compounds are compared with cromolyn sodium, which is a well-known standard mast cell stabilizer used in many clinical studies to treat various allergic diseases (Burgher et al., 1971; Businco et al., 1983; Burks and Sampson, 1988), the doses used ranging from 8 to $40 \mathrm{mg} / \mathrm{kg}$. Although all of the bioactive compounds found in the essential oil extracted from the rhizomes of $Z$. zerumbet reported in this minireview are yet to enter clinical trials, this mini-review provides an insight of the recommended doses to be used in any future studies involving these bioactive compounds. Comparisons of the doses used in animal and human studies also indicate the potential of these bioactive compounds to be developed as therapies for the treatment of allergy and allergic-related diseases in future.

\section{CONCLUSION}

This mini-review summarizes the anti-allergic and immunomodulatory properties of the major bioactive compounds found in the essential oil extracted from the rhizomes of $Z$. zerumbet in order to demonstrate the importance of $Z$. zerumbet in the treatment of allergy and allergic-related diseases, in addition to the other biomedical applications which have been widely reported and extensively studied. Future studies should focus in-depth on exploring the potential therapeutic applications of the major bioactive compounds found in the essential oil extracted from the rhizomes of $Z$. zerumbet toward various allergy-related diseases. It is also important to dissect the mechanism of action of these major bioactive compounds in order to determine how they exert their anti-allergic properties.

\section{AUTHOR CONTRIBUTIONS}

JT and CT prepared the manuscript. DI reviewed the drafts and provided important information for the completion of this manuscript. CT conceived the idea, reviewed the drafts, and provided important information for the completion of this manuscript.

\section{FUNDING}

This material is based on work supported by the Malaysia Toray Science Foundation and Putra Grant - Putra Young Initiative (IPM) (GP-IPM/2015/9455600). JT is a recipient of $\mathrm{MyPhD}$ scholarship under MyBrain15 program. 


\section{REFERENCES}

Abdelwahab, S. I., Abdul, A. B., Devi, N., Taha, M. M. E., Al-Zubairi, A. S., Mohan, S., et al. (2010). Regression of cervical intraepithelial neoplasia by zerumbone in female Balb/c mice prenatally exposed to diethylstilboestrol: involvement of mitochondria-regulated apoptosis. Exp. Toxicol. Pathol. 62, 461-469. doi: 10.1016/j.etp.2009.06.005

Baby, S., Dan, M., Thaha, A. R. M., Johnson, A. J., Kurup, R., Balakrishnapillai, P., et al. (2009). High content of zerumbone in volatile oils of Zingiber zerumbet from southern India and Malaysia. Flavour Frag. J. 24, 301-308. doi: 10.1002/ ffj. 1940

Bhuiyan, M. N. I., Chowdhury, J. U., and Begum, J. (2008). Chemical investigation of the leaf and rhizome essential oils of Zingiber zerumbet (L.) Smith from bangladesh. Bangladesh J. Pharmacol. 4, 9-12. doi: 10.3329/bjp. v4i1.845

Burgher, L. W., Elliott, R. M., and Kass, I. (1971). A perspective on the role of cromolyn sodium as an antiasthmatic agent. Chest 60, 210-213. doi: 10.1378/ chest.60.3.210

Burks, A. W., and Sampson, H. A. (1988). Double-blind placebo-controlled trial of oral cromolyn in children with atopic dermatitis and documented food hypersensitivity. J. Allergy Clin. Immunol. 81, 417-423. doi: 10.1016/00916749(88)90910-4

Businco, L., Cantani, A., Benincori, N., Perlini, R., Infussi, R., De Angelis, M., et al. (1983). Effectiveness of oral sodium cromoglycate (SCG) in preventing food allergy in children. Ann. Allergy 51, 47-50.

Butt, M. S., and Sultan, M. T. (2011). Ginger and its health claims: molecular aspects. Crit. Rev. Food Sci. Nutr. 51, 383-393. doi: 10.1080/10408391003624848

Calderón-Montaño, J. M., Burgos-Morón, E., Pérez-Guerrero, C., and LópezLázaro, M. (2011). A review on the dietary flavonoid kaempferol. Mini Rev. Med. Chem. 11, 298-344. doi: 10.2174/138955711795305335

Carlsen, K. H. (2003). Can asthma and allergy be prevented in real life? Allergy 58, 730-732. doi: 10.1034/j.1398-9995.2003.00257.x

Chaung, H. C., Huang, C. S., Lee, F. Y., and Lin, T. C. (2009). Immune modulation and anti-allergy activities of Zingiber zerumbet. U.S. Patent No. US7588788 B2. Washington, DC: U.S. Patent and Trademark Office.

da Silva, T. M., Pinheiro, C. D., Orlandi, P. P., Pinheiro, C. C., and Pontes, G. S. (2017). Zerumbone from Zingiber zerumbet (L.) smith: a potential prophylactic and therapeutic agent against the cariogenic bacterium Streptococcus mutans. bioRxiv [Preprint]. doi: 10.1101/187906

Fournial, A., Grizaud, C. M., and Mondon, P. (2013). New topical use of zerumbone. U.S. Patent No. WO2013105047 A2. Washington, DC: U.S. Patent and Trademark Office.

Hirota, R., Nakamura, H., Bhatti, S. A., Ngatu, N. R., Muzembo, B. A., Dumavibhat, N., et al. (2012). Limonene inhalation reduces allergic airway inflammation in Dermatophagoides farinae-treated mice. Inhal. Toxicol. 24, 373-381. doi: 10.3109/08958378.2012.675528

Jalil, M., Annuar, M. S. M., Tan, B. C., and Khalid, N. (2015). Effects of selected physicochemical parameters on zerumbone production of Zingiber zerumbet Smith cell suspension culture. Evid. Based Complement. Alternat. 2015:757514. doi: 10.1155/2015/757514

Jantan, I., Yassin, M., Chin, C., Chen, L., and Sim, N. (2003). Antifungal activity of the essential oils of nine Zingiberaceae species. Pharm. Biol. 41, 392-397. doi: 10.1076/phbi.41.5.392.15941

Jiang, Z., Kempinski, C., and Chappell, J. (2016). Extraction and Analysis of Terpenes/Terpenoids. Curr. Protoc. Plant Biol. 1, 345-358. doi: 10.1002/cppb. 20024

Jin, J. H., Lee, D. U., Kim, Y. S., and Kim, H. P. (2011). Anti-allergic activity of sesquiterpenes from the rhizomes of Cyperus rotundus. Arch. Pharm. Res. 34, 223-228. doi: 10.1007/s12272-011-0207-z

Kader, M. G., Habib, M. R., Nikkon, F., Yeasmin, T., Rahid, M. A., Rahman, M. M., et al. (2010). Zederone from the rhizomes of Zingier zerumbet and its anti-staphylococcal activity. Bol. Latinoam. Caribe Plant. Med. Arom. 9, 63-68.

Kalantari, K., Moniri, M., Boroumand Moghaddam, A., Abdul Rahim, R., Bin Ariff, A., Izadiyan, Z., et al. (2017). A review of the biomedical applications of Zerumbone and the techniques for its extraction from ginger rhizomes. Molecules 22:E1645. doi: 10.3390/molecules22101645

Katiyar, C., Gupta, A., Kanjilal, S., and Katiyar, S. (2012). Drug discovery from plant sources: an integrated approach. Ayu 33, 10-19. doi: 10.4103/0974-8520.100295
Khalid, M. H., Akhtar, M. N., Mohamad, A. S., Perimal, E. K., Akira, A., Israf, D. A., et al. (2011). Antinociceptive effect of the essential oil of Zingiber zerumbet in mice: possible mechanisms. J. Ethnopharmacol. 137, 345-351. doi: 10.1016/j.jep. 2011.05.043

Koga, A. Y., Beltrame, F. L., and Pereira, A. V. (2016). Several aspects of Zingiber zerumbet: a review. Rev. Bras. Farmacogn. 26, 385-391. doi: 10.1016/j.bjp.2016. 01.006

Kumar, S. C. S., Srinivas, P., and Bettadaiah, B. K. (2013). Antibacterial and antimutagenic activities of novel zerumbone analogues. Food Chem. 141, 1097-1103. doi: 10.1016/j.foodchem.2013.04.021

Kurobayashi, Y., Sakakibara, H., Yanai, T., Yajima, I., and Hayashi, K. (1991). Volatile flavor compounds of Myoga (Zingiber Mioga). Agric. Biol. Chem. 55, 1655-1657.

Lin, T. C., Chaung, H. C., Huang, C. S., and Lee, F. Y. (2013). Anti-allergy activities of Zingiber zerumbet (L.) smith. European Patent No. EP1781235 B1. Munich: European Patent Office.

Mitoshi, M., Kuriyama, I., Nakayama, H., Miyazato, H., Sugimoto, K., Kobayashi, Y., et al. (2014). Suppression of allergic and inflammatory responses by essential oils derived from herbal plants and citrus fruits. Int. J. Mol. Med. 33, 1643-1651. doi: 10.3892/ijmm.2014.1720

Murakami, A., Takahashi, D., Kinoshita, T., Koshimizu, K., Kim, H. W., Yoshihiro Nakamura, Y., et al. (2002). Zerumbone, a South east Asian ginger sesquiterpene, markedly suppresses free radical generation, pro-inflammatory protein production, and cancer cell proliferation accompanied by apoptosis: the unsaturated carbonyl group is a prerequisite. Carcinogenesis 23, 795-802. doi: $10.1093 /$ carcin/23.5.795

Murakami, A., Takahashi, M., Jiwajinda, S., Koshimizu, K., and Ohigashi, H. (1999). Identification of zerumbone in Zingiber zerumbet Smith as a potent inhibitor of 12-o-tetradecanoylphorbol-13-acetate-induced Epstein-barr virus activation. Biosci. Biotechnol. Biochem. 63, 1811-1812. doi: 10.1271/bbb.63.1811

Nam, S. Y., Chung, C. K., Seo, J. H., Rah, S. Y., Kim, H. M., and Jeong, H. J. (2014). The therapeutic efficacy of $\alpha$-pinene in an experimental mouse model of allergic rhinitis. Int. Immunopharmacol. 23, 273-282. doi: 10.1016/j.intimp.2014. 09.010

Nik Norulaini, N. A., Anuar, O., Omar, A. K. M., Abbas, F. M. A., Setianto, W. B., Fatehah, M. O., et al. (2009). Optimization of SC-CO2 extraction of zerumbone from Zingiber zerumbet (L) Smith. Food Chem. 114, 702-705. doi: 10.1016/j.foodchem.2008.09.075

Passos, G. F., Fernandes, E. S., da Cunha, F. M., Ferreira, J., Pianowski, L. F., Campos, M. M., et al. (2007). Anti-inflammatory and anti-allergic properties of the essential oil and active compounds from Cordia verbenacea. J. Ethnopharmacol. 110, 323-333. doi: 10.1016/j.jep.2006.09.032

Pawankar, R., Canonica, G. W., Holgate, S. T., Lockey, R. F., and Blaiss, M. (2013). The WAO White Book on Allergy 2013 Update. Lyon: World Allergy Organization.

Prakash, R. O., Kumar, R. K., Rabinarayan, A., and Kumar, M. S. (2011). Pharmacognostical and phytochemical studies of Zingiber zerumbet (L.) SM. Rhizome Int. J. Res. Ayurveda Pharm. 2, 698-703.

Rashid, R. A., and Pihie, A. H. L. (2005). The antiproliferative effects of Zingiber zerumbet extracts and fractions on the growth of human breast carcinoma cell lines. Malays. J. Pharm. Sci. 3, 45-52.

Reagan-Shaw, S., Nihal, M., and Ahmad, N. (2016). Dose translation from animal to human studies revisited. FASEB J. 22, 659-661. doi: 10.1096/fj.07-9574LSF

Rogerio, A. P., Andrade, E. L., Leite, D. F., Figueiredo, C. P., and Calixto, J. B. (2009). Preventive and therapeutic anti-inflammatory properties of the sesquiterpene alpha-humulene in experimental airways allergic inflammation. Br. J. Pharmacol. 158, 1074-1087. doi: 10.1111/j.1476-5381.2009.00177.x

Rout, O. P., Acharya, R., and Mishra, S. K. (2011). In vitro antioxidant potentials in leaves of coleus aromaticus benth and rhizomes of Zingiber zerumbet (L.) Sm. J. Appl. Pharm. Sci. 1, 194-198.

Ruslay, S., Abas, F., Shaari, K., Zainal, Z., Maulidiani Sirat, H., Israf, D. A., et al. (2007). Characterization of the components present in the active fractions of health gingers (Curcuma xanthorrhiza and Zingiber zerumbet) by HPLCDAD-ESIIMS. Food Chem. 104, 1183-1191. doi: 10.1016/j.foodchem.2007. 01.067

Sahebkar, A. (2011). Potential efficacy of ginger as a natural supplement for nonalcoholic fatty liver disease. World J. Gastroenterol. 17, 271-272. doi: 10.3748/wjg.v17.i2.271 
Sasidharan, S., Chen, Y., Saravanan, D., Sundram, K. M., and Yoga Latha, L. (2011). Extraction, isolation and characterization of bioactive compounds from plants' extracts. Afr. J. Tradit. Complement. Altern. Med. 8, 1-10.

Sharifi-Rad, M., Varoni, E. M., Salehi, B., Sharifi-Rad, J., Matthews, K. R., Ayatollahi, S. A., et al. (2017). Plants of the Genus Zingiber as a source of bioactive phytochemicals: from tradition to pharmacy. Molecules 22:E2145. doi: 10.3390/molecules22122145

Shieh, Y. H., Huang, H. M., Wang, C. C., Lee, C. C., Fan, C. K., and Lee, Y. L. (2015). Zerumbone enhances the Th1 response and ameliorates ovalbumin-induced Th2 responses and airway inflammation in mice. Int. Immunopharmacol. 24, 383-391. doi: 10.1016/j.intimp.2014.12.027

Shin, N. R., Shin, I. S., Jeon, C. M., Hong, J. M., Kwon, O. K., Kim, H. S., et al. (2015). Zingiber mioga (Thunb.) Roscoe attenuates allergic asthma induced by ovalbumin challenge. Mol. Med. Rep. 12, 4538-4545. doi: 10.3892/mmr.2015. 3914

Singh, C. B., Nongalleima, K. H., Brojendrosingh, S., Ningombam, S., Lokendrajit, N., and Singh, L. W. (2012). Biological and chemical properties of Zingiber zerumbet Smith: a review. Phytochem. Rev. 11, 113-125. doi: 10.1007/ s11101-011-9222-4

Singh, K., Chaturvedi, R., Barry, D. P., Coburn, L. A., Asim, M., Lewis, N. D., et al. (2011). The apolipoprotein E-mimetic peptide COG112 inhibits NFkappaB signaling, proinflammatory cytokine expression, and disease activity in murine models of colitis. J. Biol. Chem. 286, 3839-3850. doi: 10.1074/jbc.M110. 176719

Sirirugsa, P. (1995). The genus Hedychium (Zingiberaceae) in Thailand. Nord. J. Bot. 15, 301-304. doi: 10.1111/j.1756-1051.1995.tb00156.x

Somchit, M. N., Shukriyah, M. H. N., Bustamam, A. A., and Zuraini, A. (2005). Anti-pyretic and analgesic activity of Zingiber zerumbet. Int. J. Pharm. 1, 277-280. doi: 10.3923/ijp.2005.277.280

Sulaiman, M. R., Mohamad, T. A. S. T., Mossadeq, W. M. S., Moin, S., Yusof, M., Mokhtar, A. F., et al. (2010). Antinociceptive activity of the essential oil of Zingiber zerumbet. Planta Med. 76, 107-112. doi: 10.1055/s-00291185950

Sun, J. (2007). D-Limonene: safety and clinical applications. Altern. Med. Rev. 12, 259-264.

Takada, Y., Murakami, A., and Aggarwal, B. B. (2005). Zerumbone abolishes NF-kappaB and IkappaBalpha kinase activation leading to suppression of antiapoptotic and metastaticgene expression, upregulation of apoptosis, and downregulation of invasion. Oncogene 24, 6957-6969. doi: 10.1038/sj.onc. 1208845

Tewtrakul, S., and Subhadhirasakul, S. (2007). Anti-allergic activity of some selected plants in the Zingiberaceae family. J. Ethnopharmacol. 109, 535-538. doi: 10.1016/j.jep.2006.08.010

Watanabe, K., Yano, S., Horie, T., Kachia, R. S., Ikegami, F., Yamamoto, Y., et al. (1994). Borneol as allergy inhibitor. Japan Patent No. JP06211713. Chiyoda: Japan Patent Office.

Yob, N. J., Jofrry, S. M., Affandi, M. M., The, L. K., Salleh, M. Z., and Zakaria, Z. A. (2011). Zingiber zerumbet (L.) Smith: a review of its ethnomedicinal, chemical, and pharmacological uses. Evid. Based Complement. Alternat. Med. 2011:543216. doi: 10.1155/2011/ 543216

Conflict of Interest Statement: The authors declare that the research was conducted in the absence of any commercial or financial relationships that could be construed as a potential conflict of interest.

Copyright (c) 2018 Tan, Israf and Tham. This is an open-access article distributed under the terms of the Creative Commons Attribution License (CC BY). The use, distribution or reproduction in other forums is permitted, provided the original author(s) and the copyright owner are credited and that the original publication in this journal is cited, in accordance with accepted academic practice. No use, distribution or reproduction is permitted which does not comply with these terms. 